\title{
Functional Performance of an Enabling Atmosphere Revitalization Subsystem Architecture for Deep Space Exploration Missions
}

\author{
Jay L. Perry ${ }^{1}$, Morgan B. Abney ${ }^{2}$, Kenneth R. Frederick ${ }^{3}$, Zachary W. Greenwood ${ }^{4}$, Matthew J. Kayatin ${ }^{5}$, \\ Robert L. Newton ${ }^{6}$, Keith J. Parrish ${ }^{7}$, Monsi C. Roman ${ }^{8}$, and Kevin C. Takada ${ }^{9}$ \\ NASA George C. Marshall Space Flight Center, Huntsville, Alabama, 35812, USA \\ Lee A. Miller ${ }^{10}$ \\ ECLS Technologies, LLC, Huntsville, Alabama, 35802, USA \\ Joseph P. Scott ${ }^{11}$ \\ Jacobs Engineering, Huntsville, Alabama, 35806, USA \\ and \\ Christine M. Stanley ${ }^{12}$ \\ Qualis Corp., Huntsville, Alabama, 35806, USA
}

\begin{abstract}
A subsystem architecture derived from the International Space Station's (ISS) Atmosphere Revitalization Subsystem (ARS) has been functionally demonstrated. This ISSderived architecture features re-arranged unit operations for trace contaminant control and carbon dioxide removal functions, a methane purification component as a precursor to enhance resource recovery over ISS capability, operational modifications to a water electrolysis-based oxygen generation assembly, and an alternative major atmospheric constituent monitoring concept. Results from this functional demonstration are summarized and compared to the performance observed during ground-based testing conducted on an ISS-like subsystem architecture. Considerations for further subsystem architecture and process technology development are discussed.
\end{abstract}

\section{Nomenclature}

$\begin{array}{ll}C & =\text { Celsius } \\ \mathrm{cm} & =\text { centimeter } \\ d & =\text { day } \\ \mathrm{h} & =\text { hour } \\ \mathrm{kg} & =\text { kilogram } \\ \mathrm{kPa} & =\text { kilopascal }\end{array}$

${ }^{1}$ Lead Aerospace Engineer, Space Systems Dept., NASA-MSFC/ES62.

${ }^{2}$ Aerospace Engineer, Space Systems Dept., NASA-MSFC/ES62, AIAA Member

${ }^{3}$ Test Engineer, Space Systems Dept., NASA-MSFC/ES62.

${ }_{5}^{4}$ Aerospace Engineer, Space Systems Dept., NASA-MSFC/ES62.

${ }^{5}$ Aerospace Engineer, Space Systems Dept., NASA-MSFC/ES62.

${ }^{6}$ Chemist, Space Systems Dept., NASA-MSFC/ES62.

${ }^{7}$ Test Director, Space Systems Dept., NASA-MSFC/ES62.

${ }^{8}$ Project Manager, Technology Development and Transfer Office., NASA-MSFC/ZP31.

${ }^{9}$ Aerospace Engineer, Space Systems Dept., NASA-MSFC/ES62.

${ }^{10}$ Engineer, ECLS Technologies, NASA-MSFC/ES62.

${ }^{11}$ ECLSS Chemist, Jacobs Engineering ESSSA Group, NASA-MSFC/ES62.

${ }^{12}$ ECLSS Engineer, Qualis Corp. ESSSA Group, NASA-MSFC/ES62. 


$\begin{array}{ll}m & =\text { meter } \\ m g & =\text { milligram } \\ m l & =\text { milliliter } \\ m m & =\text { millimeter } \\ P a & =\text { Pascal } \\ p p m & =\text { parts per million (volume) } \\ \text { ppb } & =\text { parts per billion (volume) } \\ \mu m & =\text { micrometer } \\ \% & =\text { percent }\end{array}$

\section{Introduction}

$\mathrm{H}_{\text {tic }}^{\mathrm{in}}$ IGHLY efficient and reliable resource recovery by a spacecraft atmosphere revitalization (AR) subsystem is the ultimate goal for environmental control and life support (ECLS) system designers to enable crewed deep space exploration missions. While the ISS ECLS system approaches this functional goal, flight operational experience has identified areas for improvement that must be addressed before humanity can embark confidently on deep space exploration missions. Opportunities to increase oxygen $\left(\mathrm{O}_{2}\right)$ and water recovery percentages as well as to improve equipment functional reliability exist.

The National Aeronautics and Space Administration (NASA) Advanced Exploration Systems (AES) Atmosphere Resource Recovery and Environmental Monitoring (ARREM) for Long Duration Exploration Project's principal objective is to address technical areas for improvement over the ISS architecture. Maturing integrated atmosphere revitalization (AR) and environmental monitoring (EM) subsystems based on the International Space Station (ISS) AR subsystem architecture is a strategy for reducing technical development and mission risk, lowering lifecycle costs, and demonstrating operational process design and system architectural concepts for future crewed missions beyond Earth orbit. The ISS AR and EM architectures are loosely coupled which may cause developmental and operational inefficiencies. The ARREM Project seeks a technical solution where the AR and EM subsystems are more closely coupled.

The specific objectives and goals of the ARREM Project are the following:

1) To demonstrate an evolved ISS AR and EM subsystem architecture via targeted advancements that benefit ISS operations and exploration missions beyond low Earth orbit (LEO).

2) To assess equipment configurations that offer the greatest potential for maximizing process technology and hardware component commonality across a variety of mission scenarios and vehicle concepts anticipated in a flexible exploration framework.

3) To advance the technical maturity of candidate process technologies for flexible AR and EM subsystem architectures to achieve risk reduction and developmental cost reduction to flight project development programs.

4) To develop a set of resource recovery capabilities that can be integrated in modular fashion with common core AR and EM subsystem equipment to allow mission planners flexibility for extending crewed mission durations without compromising core equipment functionality.

Testing at component, assembly, and integrated subsystem levels is necessary to satisfy the ARREM Project objectives. Integrated subsystem testing will be accomplished in progressive stages which will be referred to as "cycles" for the purposes of the project. The ARREM Project integrated testing cycles are the following:

1) Cycle 0: ISS functional testing to establish the basis for comparison for successive integrated testing cycles.

2) Cycle 1: Modified ISS architecture incorporating improved trace contaminant and carbon dioxide $\left(\mathrm{CO}_{2}\right)$ removal adsorbents; trace contaminant removal oxidation catalysts; partial $\mathrm{CO}_{2}$ reduction byproduct processing; water electrolysis oxygen $\left(\mathrm{O}_{2}\right)$ generation and alternative major atmospheric constituent monitoring.

3) Cycle 2: Alternative process gas drying equipment; advanced $\mathrm{CO}_{2}$ reduction byproduct processing; and alternative major constituent and volatile organic compound monitoring.

4) Cycle 3: Advanced $\mathrm{CO}_{2}$ removal and compression; complete $\mathrm{CO}_{2}$ reduction byproduct processing; advanced environmental monitoring sensor array; ammonia catalytic reduction.

Five NASA field centers participate in the ARREM Project-Ames Research Center (ARC), Glenn Research Center (GRC), Johnson Space Center (JSC), Jet Propulsion Laboratory (JPL), Kennedy Space Center (KSC), and Marshall Space Flight Center (MSFC). Each field center provides subject-matter expertise in the assessing, maturing and testing the AR and EM technologies with the ultimate goal of improving reliability and reducing resources like mass, power, volume and consumables. 


\section{Architectural Basis for Comparison vs. Cycle 1 Testing Architecture}

Applying the ISS AR subsystem equipment architecture has been proposed as a leading strategy for enabling future crewed deep space exploration missions. ${ }^{1-2}$ The ISS AR subsystem architecture was assessed according to functional trade spaces to establish a basis for comparison. ${ }^{3}$ These trade spaces serve to define the project work breakdown structure within which technical tasks are conducted to reach project goals. Integrated functional architectures representing the ISS AR subsystem and changes indicated by the architectural assessment to the ISS architecture are tested in a sealed environmental chamber using a phased approach. ${ }^{4}$ The testing series began with the Cycle 0 Resource Recovery Functional Demonstration (R2FD) test to establish the basis for comparison. The R2FD test used ISS AR subsystem flight-like developmental hardware configured according to the ISS AR subsystem architecture. The ARREM Cycle 1 test used nearly the same test equipment as the R2FD test but configured differently to realize targeted functional improvements and subsystem complexity reductions. The following discussion briefly describes the R2FD and Cycle 1 integrated testing configurations.

\section{A. The Basis for Comparison-the ISS Architecture}

The R2FD test configuration, shown schematically by Fig. $1,{ }^{4}$ duplicates the ISS AR subsystem architecture. Over time, that architecture has evolved to enable a higher degree of loop closure by adding $\mathrm{O}_{2}$ generation and $\mathrm{CO}_{2}$ reduction functions. The core ISS AR subsystem equipment used for the R2FD test included a developmental $\mathrm{CO}_{2}$ removal assembly (dev-CDRA), a Sabatier-based $\mathrm{CO}_{2}$ reduction assembly development unit (SDU), the ISS trace contaminant control system development unit 1.1 (TCCS dev-1.1), and the ISS developmental $\mathrm{O}_{2}$ generation assembly (dev-OGA). The dev-OGA equipment was not operational in time for the test so the function was simulated using facility-provided $\mathrm{O}_{2}$ and hydrogen $\left(\mathrm{H}_{2}\right)$ feeds to the chamber atmosphere and the SDU, respectively. $\mathrm{A} \mathrm{CO}_{2}$ management assembly (CMA) consisting of a two-stage commercial compressor and accumulator tanks that
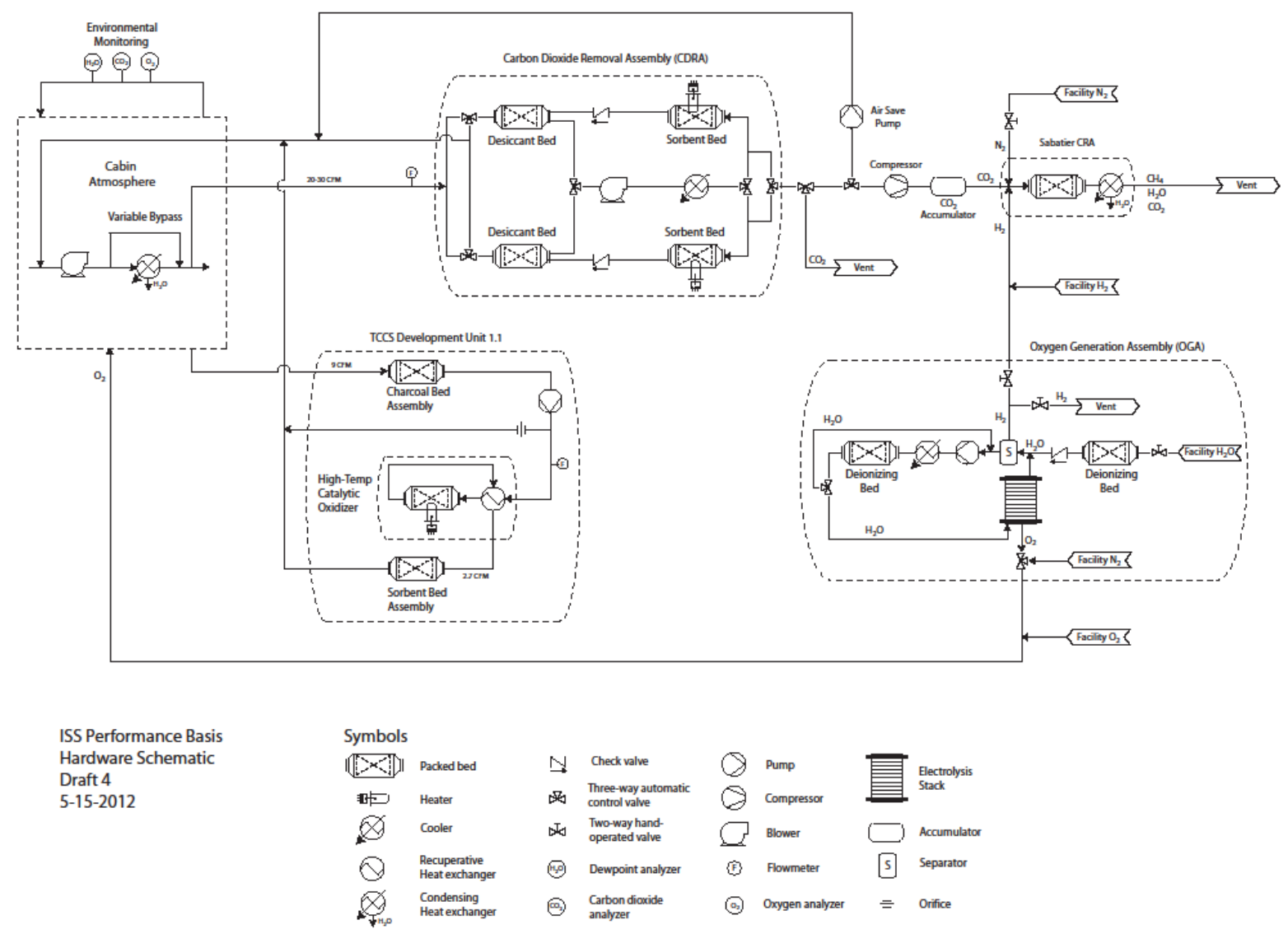

Figure 1. Resource Recovery Functional Demonstration test schematic. ${ }^{4}$ Developmental test articles for $\mathrm{CO}_{2}$ removal, $\mathrm{CO}_{2}$ reduction, $\mathrm{CO}_{2}$ management, trace contaminant control, and major constituent monitoring were included in the test equipment complement. Oxygen generation was functionally simulated. 
dampens flow rate pulses to the SDU. Because the commercial compressor discharge pressure was $414 \mathrm{kPa}$ compared to the flight CRA compressor's $827 \mathrm{kPa}$, the accumulator volume was increased from 19.8 liters to 48.1 liters. An array of commercially available analyzers provided the major constituent analysis (MCA) function. ${ }^{5}$

\section{B. ARREM Project Cycle 1 Architecture}

The functional architecture for the ARREM Project Cycle 1 test shown by Fig. 2 is an effort to reduce the total AR subsystem complexity and part count with minimal change to ISS AR subsystem components. ${ }^{4}$ The test included all of the same equipment used during the R2FD test with two exceptions. First, the TCCS equipment was re-arranged with a thermal catalytic oxidizer assembly integrated directly with the dev-CDRA and a fixed activated carbon bed integrated in parallel with the cabin condensing heat exchanger. The objective was to eliminate an avionics box, blower with acoustic treatment, and a post-sorbent bed assembly while maintaining full trace contaminant control functionality. The catalytic oxidizer assembly also incorporated an engineered ultra-short channel metal monolith catalytic reactor

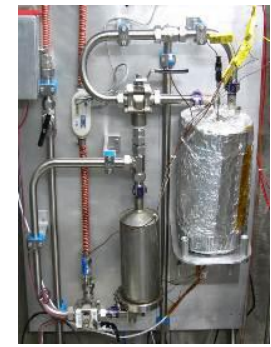

Figure 3. Trace and $\mathrm{CO}_{2}$ management equipment in the ARREM Cycle 1 test. a) thermal catalytic oxidizer assembly; b) piston compressor. design that has been demonstrated to be more energy efficient and more easily maintained in flight than the ISS TCCS catalytic reactor design. ${ }^{6}$ These changes may realize mass and volume savings up to $12.4 \mathrm{~kg}$ and 14.7 liters, respectively, over the ISS AR subsystem architecture while maintaining trace contaminant removal performance. The CMA compressor was replaced with a flight-like piston compressor manufactured by Southwest Research Institute. This change allowed the $\mathrm{CO}_{2}$ accumulator tank volume to be reduced to the ISS flight-like 19.8 liters. The SDU was configured to test a methane purification postprocessing stage. The MCA function was again provided by the array of commercially available instruments.
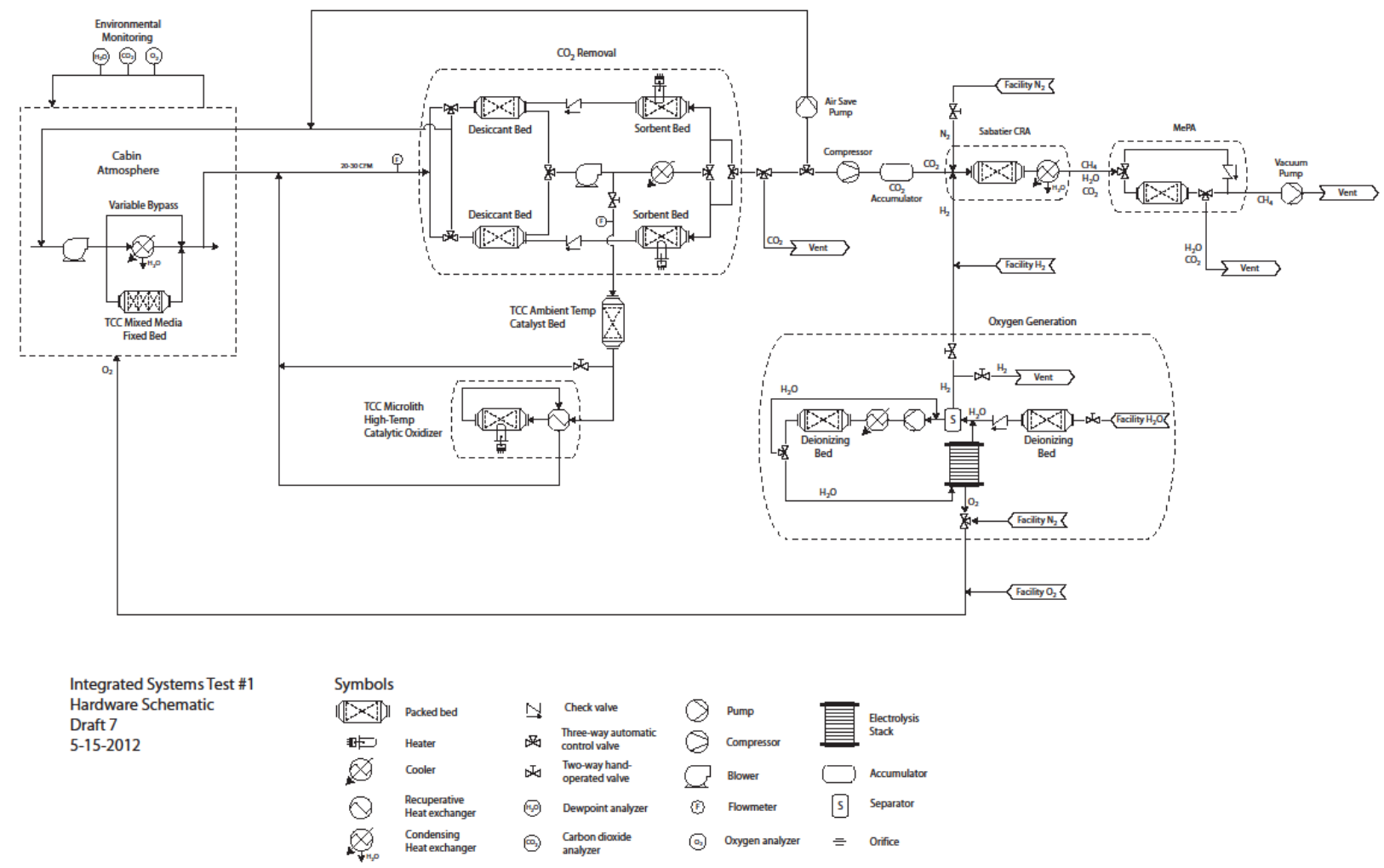

Figure 2. ARREM Project Cycle 1 integrated testing architecture. ${ }^{4}$ Trace contaminant control system components are integrated differently relative to $\mathrm{CO}_{2}$ removal and cabin ventilation equipment. Capability is provided to demonstrate $\mathrm{CO}_{2}$ reduction byproduct post-processing. Oxygen generation was functionally simulated. 


\section{Testing Facility and Methods}

The testing facility is a $9,290-\mathrm{m}^{2}$ high-bay area containing bench-scale and sealed chamber testing platforms that allow a full range of testing capabilities ranging from bench-scale demonstration of individual components and assemblies through fully-integrated subsystems and systems. Since 1985, the facility has been instrumental in the development, performance evaluation, and sustaining engineering support for the ISS ECLS system equipment as well as evaluating new technical developments in ECLS system process technologies.

The 90.6- $\mathrm{m}^{3}$ Environmental Chamber (EChamber) provided the integrated testing infrastructure during the R2FD and ARREM Cycle 1 integrated testing series. The EChamber, shown by Fig. 4, is outfitted with test support equipment to inject trace chemical contaminants; to provide chamber ventilation, temperature, and humidity control; to provide chamber atmospheric pressure control; to simulate human metabolic loads; to monitor the chamber's internal conditions; to provide a space vacuum simulation resource; and to accommodate thermal and power loads in support of assembly-level and system-level integrated tests. Automated test operations control and data acquisition are provided via LabVIEW (National Instruments) software and data archiving is provided by the NASA MSFC Payloads and Components Real-time Automated Test System (PACRATS) software. The EChamber atmospheric pressure is selectable from slightly above local barometric pressure to $<55.2 \mathrm{kPa}$. An enclosure surrounds the EChamber to minimize the effects of

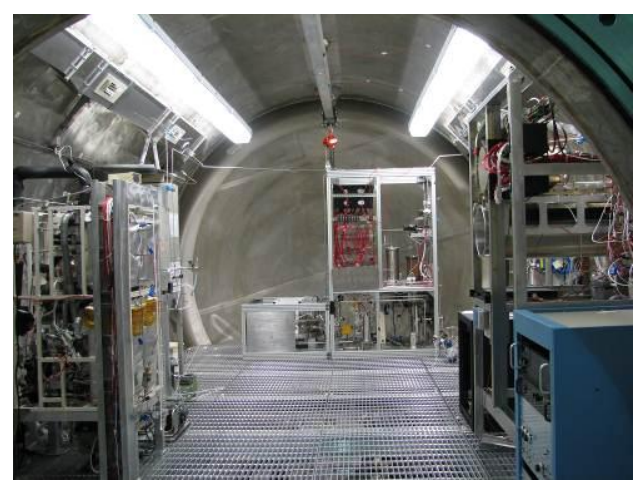

Figure 4. An EChamber interior view. Carbon dioxide removal (left), trace contaminant control (right), and oxygen generation equipment (rear) are visible. external temperature changes in the facility high bay on the EChamber's internal pressure. The EChamber's in-line analytical methods provide data necessary for determining that the test objectives are being met. For this reason, details on the analytical methods used are provided.

The analytical instrumentation used during the R2FD and ARREM Cycle 1 testing series can be divided into two groups - instruments used for trace contaminant propagation studies and instruments used to monitor major constituents of the chamber atmosphere. The latter instruments also serve as a test article for the MCA function. The trace contaminant monitoring instruments were located in the large high bay facility outside the EChamber enclosure. The temperature inside the high bay was maintained at approximately $23{ }^{\circ} \mathrm{C}$ throughout the duration of the tests. Sample delivery from the EChamber to the trace contaminant instrumentation was accomplished via a 6.4$\mathrm{mm}$ diameter $\times 12.2-\mathrm{m}$ stainless steel, unheated transfer tube. This tubing was solvent-cleaned and extensively purged with dry nitrogen $\left(\mathrm{N}_{2}\right)$ prior to being placed into service. The sample flow was assisted via a small pump located near the analytical instrumentation. A multiport valve provided flexibility with respect to sampling location inside the EChamber. The MCA instrumentation was rack-mounted inside the EChamber. These instruments sampled the EChamber atmosphere directly, requiring no transfer lines.

\section{Trace Contaminant Monitoring Method}

All quantitative analyses with respect to trace contaminants were carried out with an Agilent 6890 gas chromatograph (GC) utilizing a single analytical column and a flame ionization detector. The column was a 30-m long intermediate polarity capillary column with a $0.53-\mathrm{mm}$ inner diameter. The film thickness was $3.0 \mu \mathrm{m}$. Ultra high purity helium was used as the carrier gas. Facility grade $\mathrm{N}_{2}$ was used to perform instrument blanks between sample runs.

Sample concentration and delivery to the GC was accomplished with a Markes TT24-7 Thermal Desorption System. This is an electrically cooled, two-trap system with the traps operating sequentially. The measurement frequency consisted of sampling for 10 minutes, being repeated approximately every 25 minutes. The traps were packed with Tenax $\mathrm{TA}^{\mathrm{TM}}$ and Unicarb ${ }^{\mathrm{TM}}$ in order to retain both low and high volatility compounds.

The airborne concentration inside the EChamber for the volatile organic compounds (VOCs) generated from the liquid injection mixture were expected to be in the low parts per million range. The exception being during the initial 'spiking' of the EChamber at the start of the test once the door had been closed and sealed. This step was necessary in order to passivate the inner surfaces of the EChamber itself as well as the various items of hardware contained inside. The initial spiking was achieved by using five 1-ml injections in rapid succession. 
All analytical target compounds were calibrated using standard multipoint methods summarized by Table 1 . During the R2FD test, both liquid and commercially purchased gas standards were used for calibrating the GC. The liquid phase standards were first injected onto a sorbent tube. Next, the sorbent tube was desorbed at high temperature onto the cold traps of the Markes 24-7 unit. Finally, the cold traps were rapidly heated, causing the VOCs to desorb and flow onto the GC column via a heated transfer line. The gas phase standards, contained in pressurized cylinders, were introduced directly onto the cold traps in the same fashion as a typical air sample. During the ARREM Cycle 1 test, GC calibration was achieved using gas phase standards generated on demand via a National Institute for Standards and Technology (NIST)-traceable permeation tube gas generator manufactured by Kin-Tek. While the GC method error was compound specific, overall, the order of magnitude was in the $25 \%-30 \%$ range.

A second GC, a recently-procured Agilent 7890 utilizing a single analytical column with both a flame ionization and a mass selective detector (MSD) was employed for screening and unknown compound identification during portions of ARREM Cycle 1 tests. This GC is coupled with a Gerstel Thermal Desorption System and in the future will be used in conjunction with the Agilent 6890/Markes 24-7 system to provide more robust testing capabilities than were previously possible.

2. Major Constituent Analysis Instrumentation

The major constituents monitored during the R2FD and ARREM Cycle 1 investigations included $\mathrm{O}_{2}, \mathrm{CO}_{2}$, and water vapor. An instrument array demonstrated in 2002 through 2003 and described by Ref. 5 provided the function. In this array, shown by Fig. 5, $\mathrm{O}_{2}$ was monitored using an Oxigraf Model $\mathrm{O}_{2}$ Oxygen analyzer. This device utilizes a solid-state laser diode absorption system and measures $\mathrm{O}_{2}$ concentrations ranging from $0.01 \%$ to $100 \%$ by volume. Carbon dioxide was monitored using a Sable Systems CA-2A analyzer, which utilizes solid-state infrared absorption technology and can measure between $1 \mathrm{ppm}$ and 10 percent $\mathrm{CO}_{2}$. Relative humidity was measured using a Sable Systems RH-100 meter, employing a solid-state, thin film capacitance detection system. This instrument is capable of measuring relative humidity between $0.01 \%$ and $99 \%$. The instrument array performance was stable throughout both the R2FD and ARREM Cycle 1 testing series.

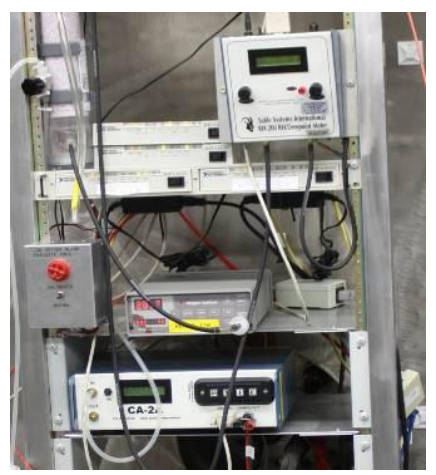

Figure 5. Major constituent analysis instrument array.

\section{Resource Recovery Functional Demonstration Results Summary}

Specific testing objectives were focused on understanding the propagation of trace contaminants through the core AR subsystem equipment and the resulting effect on the purity of product $\mathrm{CO}_{2}$ being fed to the SDU. The TCCS showed the ability to keep the EChamber atmosphere trace contaminant concentrations within the expected range while processing the simulated contaminant loading of a 3-person crew. The average humidity condensate removed from the EChamber was $7.86 \mathrm{~kg} / \mathrm{d}$. The CMA performed properly according to the control logic but some inefficiencies were observed that can affect SDU operations due to $\mathrm{CO}_{2}$ accumulator pressure maintenance challenges when the pressure dropped below $137.9 \mathrm{kPa}$. Low accumulator pressure causes the SDU to transition to standby mode. The dev-CDRA performance analysis confirmed that the operation during R2FD testing compared with previous operations as far as $\mathrm{CO}_{2}$ removal efficiency with a 3-person metabolic load. The following summarizes the principal observations from the R2FD testing series. 


\section{A. General Testing Observations}

Testing was conducted in the EChamber maintained at conditions summarized by Table 2 while simulating a three-person metabolic load. All facility support equipment performed as expected during the R2FD testing series. Before testing, the chamber leakage rate was determined to be approximately $0.027 \mathrm{~kg} / \mathrm{h}$ when the internal pressure was held at a minimum $400 \mathrm{~Pa}$ above the prevailing barometric pressure. However, test data indicated that the leakage rate was higher than expected at $2.27 \mathrm{~kg} / \mathrm{h}$ due to an undermined leakage path. Also, a leaking solenoid valve resulted in $\mathrm{CO}_{2}$ being lost to the space vacuum simulator which in turn affected the duty cycle of the SDU.
Table 2. EChamber conditions for R2FD testing.

\begin{tabular}{|l|c|}
\hline \multicolumn{1}{|c|}{ PARAMETER } & RANGE \\
\hline Total pressure & $400-933 \mathrm{~Pa}$ gauge \\
\hline Oxygen partial pressure & $20.58 \pm 0.14 \mathrm{kPa}$ \\
\hline Carbon dioxide partial pressure & $400 \pm 67 \mathrm{~Pa}$ \\
\hline Temperature & $21 \pm 2.8^{\circ} \mathrm{C}$ \\
\hline Relative humidity & $50 \pm 5 \%$ \\
\hline Contaminant injection rate & $230 \mathrm{mg} /$ hour $^{*}$ \\
\hline
\end{tabular}

*Percent by mass: methanol (10.7), ethanol (67.1), 2-propanol (4.8), ethanal (7.6), dimethylbenzene (2.3), dichloromethane (1.3), 2 propanone (6.2)

\section{B. Carbon Dioxide Removal Performance}

The dev-CDRA equipment used in the R2FD test is shown by Fig. 5. This equipment was configured to mimic the performance of the CDRA-3 hardware aboard the ISS. The ISS CDRA consists of a four-bed molecular sieve (4BMS) process comprised of two desiccant beds and two $\mathrm{CO}_{2}$ adsorbent beds. Ancillary components include a blower, air-save pump, heat exchanger, valves, and sensors. Details on the ISS CDRA's operation are provided by Refs. 7 and 8. Table 3 summarizes the dev-CDRA process operating conditions.

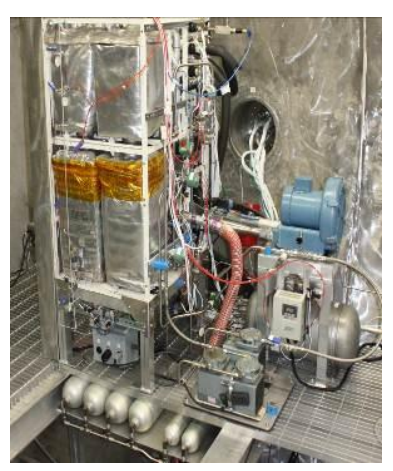

Figure 5. Carbon dioxide removal equipment. $\mathrm{CO}_{2}$ accumulator tanks and the compressor are visible.
The R2FD testing provided performance data to serve as the basis for comparison for later ARREM Project testing cycles. The objectives for the CDRA were twofold-first, to verify performance relative to previous ground tests to determine that the devCDRA performed within an acceptable range and second, to compare the dev-CDRA performance with the ISS protoflight CDRA performance.

The dev-CDRA was subjected to a series of tests in $2005 .{ }^{9}$ Data from two of these tests are used in the performance comparison. The flight CDRA was put through a series of acceptance tests prior to delivery to the ISS. Data from CDRA Protoflight Acceptance Test (PAT) Runs 12, 13, and 14 conducted on the ISS Lab Module CDRA equipment serve as the basis for comparison for R2FD testing and subsequent testing phases. Data acquired from the CDRA PAT runs are the benchmark for comparing ground-based CDRA development unit performance to required flight performance. Figure 6 compares the dev-CDRA equipment performance observed during R2FD testing and testing conducted in 2005 with the ISS CDRA PAT results. The dev-CDRA performance data show the unit performing consistently with performance observed in 2005. This indicated that the dev-CDRA hardware performed as expected and that performance is repeatable over time. In addition, the performance compares favorably with the ISS protoflight CDRA test data. The $\mathrm{CO}_{2}$ removal performance observed during the R2FD testing series complied with the ISS CDRA performance specification.
Table 3. Dev-CDRA process conditions.

\begin{tabular}{|l|c|}
\hline \multicolumn{1}{|c|}{ PARAMETER } & VALUE \\
\hline Inlet temperature & $4.4-10^{\circ} \mathrm{C}$ \\
\hline Inlet dewpoint & $4.4-10^{\circ} \mathrm{C}$ \\
\hline Flow rate & $34.7 \mathrm{~m}^{3} / \mathrm{h}$ \\
\hline Precooler coolant temperature & $3.3-5.6^{\circ} \mathrm{C}$ \\
\hline Coolant flow rate & $1.9-2.0 \mathrm{~L} /$ minute \\
\hline Half cycle duration & 155 minutes \\
\hline Heater temperature setting & $204{ }^{\circ} \mathrm{C}$ \\
\hline
\end{tabular}

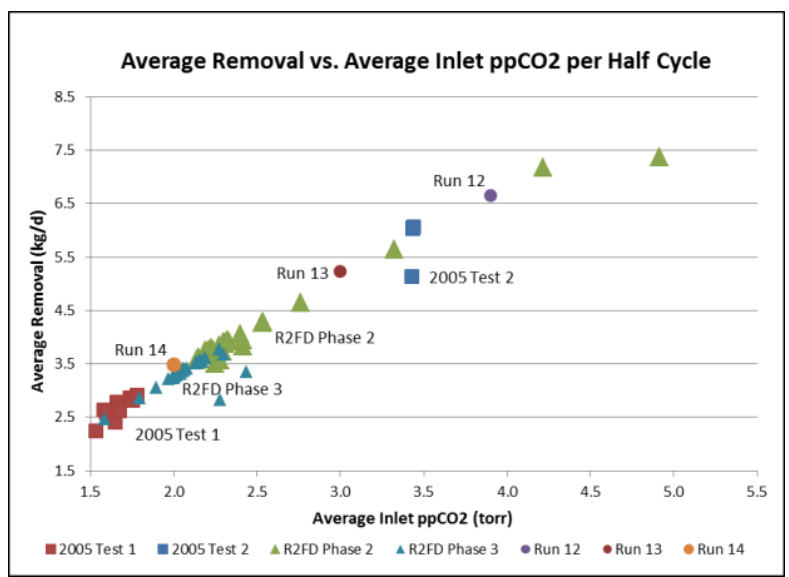

Figure 6. Developmental CDRA performance. 


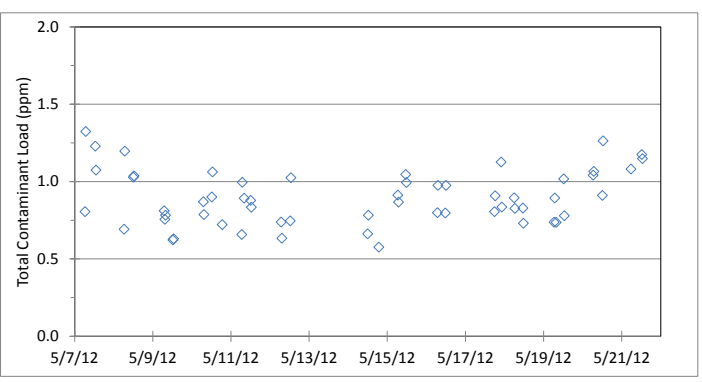

Figure 7. Total EChamber atmosphere trace contaminant loading during the R2FD test.

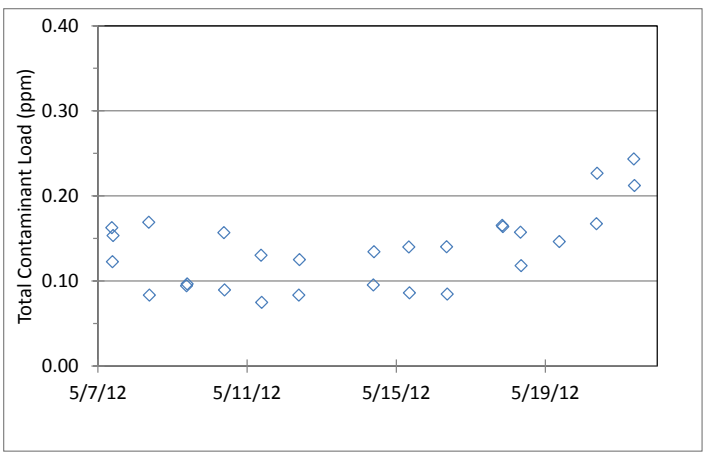

Figure 8. Total TCCS effluent trace contaminant loading during the R2FD test.
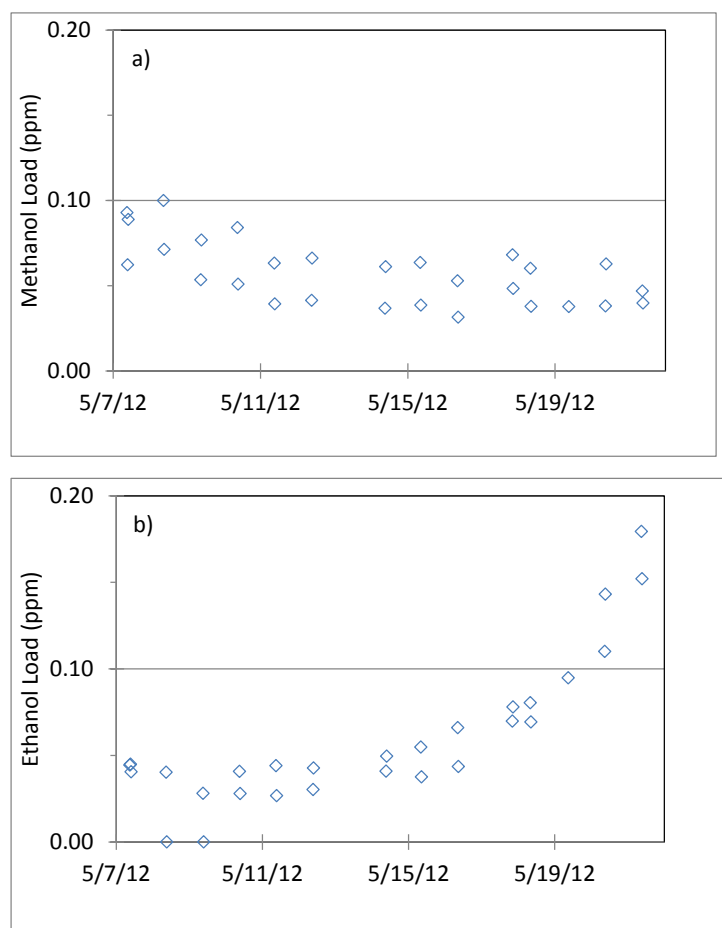

Figure 9. TCCS effluent trace contaminant loading for a) methanol and b) ethanol during the R2FD test.

\section{Trace Contaminant Control Performance}

The R2FD total trace contaminant loading in the chamber atmosphere during test duration is shown by Fig. 7. Note that GC calibrations were carried out using K-bottle standards for the R2FD test, however, Kin-Tek gas generator tubes were used for calibration during ARREM Cycle 1 test. In order to maintain consistency with the ARREM Cycle 1 testing data calibration methodology the R2FD testing data set was biased upward by $30 \%$. The mean contaminant loading over the R2FD plateau shown in Fig. 7 was found to be $1.14 \mathrm{ppm}$ which is consistent with the expected concentration when all removal routes are accounted for. The TCCS provides the primary active trace contaminant control function; however, its function is assisted by incidental removal provided by absorption in humidity condensate, the dev-CDRA, and EChamber leakage. Such trace contaminant removal functional assist has been observed and characterized previously. ${ }^{10-11}$

Evaluation of the TCCS performance determined a mean effective overall $88 \%$ contaminant removal efficiency. As displayed by Fig. 8, the TCCS effluent was monitored over time. Although stable for much of the test duration, the total contaminant concentration in the TCCS effluent appeared to trend upwards near the test's conclusion. The mean contaminant loading was found to be $0.136 \mathrm{ppm}$, although skewed by the loading trend from 5/19/12 onward.

In order to better understand the decrease in TCCS performance near test conclusion, individual chemical species loads were examined. Figure 9a displays the TCCS effluent for methanol and Figure 9b displays the ethanol dataset. Initially, the total trace loading shown by Fig. 8 is comprised by predominately methanol as shown in Fig. 9a. The TCCS removal of methanol shows a net decrease over testing. Conversely, as shown by Fig. 9b, the ethanol contribution to the total trace loading increases and becomes dominant near test conclusion, influencing the total trace loading to trend upwards. Assuming that the TCCS flow rates remained constant, the monotonic increase in ethanol concentration indicated fixed activated carbon bed breakthrough.

In order to determine the effect of trace contaminants on the SDU, the $\mathrm{CMA} \mathrm{CO}_{2}$ accumulator tank, located downstream from the CDRA subsystem, was sampled and analyzed for VOC content. The CMA $\mathrm{CO}_{2}$ accumulator feeds into the SDU and serves as a buffer to eliminate any feed interruption. Figure 10 displays the total contaminant loading over the test duration. The dataset appears to trend down with time. A linear data regression trend line serves to guide the eye. The $\mathrm{CMA} \mathrm{CO}_{2}$ accumulator tank had a mean concentration of $0.041 \mathrm{ppm}$. 


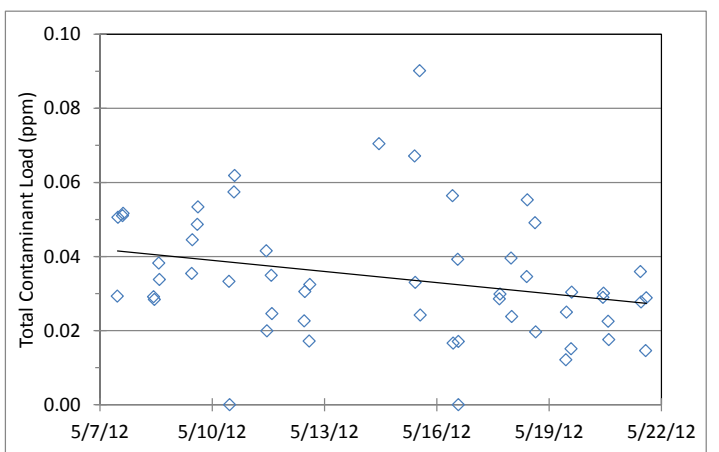

Figure 10. CMA $\mathrm{CO}_{2}$ accumulator trace contaminant loading trend during the R2FD test.

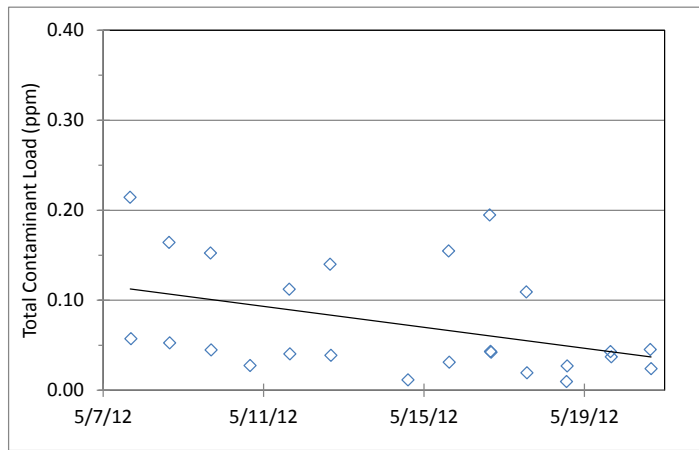

Figure 11. Metabolic simulation $\mathbf{O}_{2}$ concentrator trace contaminant loading during the R2FD test.

Serving as a contaminant removal route, the $\mathrm{O}_{2}$ concentrator that provided the metabolic $\mathrm{O}_{2}$ consumption simulation entrained trace contaminant species as shown by Fig. 11. The $\mathrm{O}_{2}$ concentrator had a mean concentration of $0.073 \mathrm{ppm}$ and trended down with testing. A linear data regression trend line serves to guide the eye.

\section{Carbon Dioxide Reduction Performance}

Following removal of metabolic $\mathrm{CO}_{2}$ by the CDRA, the gas is subsequently compressed and stored in tanks in the CMA. The $\mathrm{CO}_{2}$ is then fed, as required, to the SDU for reduction. Based on previous testing at NASA MSFC and Hamilton Sundstrand, there was concern that VOC accumulation in the CMA may ultimately reduce the efficiency of the SDU or cause permanent damage to the catalyst material. For this reason, two tests were conducted. First, VOC loading of the accumulated $\mathrm{CO}_{2}$ was monitored. Second, the performance of the SDU was observed when fed VOC-loaded $\mathrm{CO}_{2}$ from the accumulator. The observed VOC accumulation and the corresponding SDU performance effects are described below.

\section{VOC Loading of Carbon Dioxide}

During R2FD testing, VOC loading of accumulated $\mathrm{CO}_{2}$ was monitored for a total of fifteen days. Seven VOCs were shown to accumulate in the compressed $\mathrm{CO}_{2}$, as shown in Fig. 12. Previous testing by Hamilton Sundstrand suggested the VOCs expected to cause a negative effect on $\mathrm{CO}_{2}$ reduction performance were dichloromethane and 1,3-dimethylbenzene (m-xylene). However, reduced performance was tested at $576 \mathrm{ppm}$ and 26 ppm, respectively. Concentrations of dichloromethane and 1,3-dimethylbenzene, two compounds of concern with respect to SDU performance, were below detectable limits in the $\mathrm{CO}_{2}$ product during R2FD testing. These observations indicate that the VOCs, when present in the cabin atmosphere at concentrations representative of a crewed spacecraft cabin, should not be expected to cause any adverse effects on the SDU during operation.

2. Effects of VOCs on Carbon Dioxide Reduction Performance

During later R2FD testing phases, the SDU was fed $\mathrm{CO}_{2}$ from the CMA accumulator tanks. Performance of the SDU was determined based on water accumulation rate. SDU performance during the R2FD test was compared with results from testing conducted in 2009. The average water accumulation rate observed during R2FD testing was approximately $0.37 \mathrm{~cm} /$ minute. In 2009 , the average accumulation rate was 0.44 $\mathrm{cm} /$ minute. However, the condensing heat exchanger operated at a temperature of $26.7^{\circ} \mathrm{C}$ in 2009 and 33.3 ${ }^{\circ} \mathrm{C}$ in 2011 due to the higher ambient temperature in the EChamber. When the water accumulation rates are back-calculated for overall $\mathrm{CO}_{2}$ reduction, operation in 2009 was shown to have $\sim 84 \% \mathrm{CO}_{2}$ conversion while operation in 2011 was shown to have $\sim 86 \%$ conversion. The difference between these values was within the measurement method's error. Thus, it was determined that the presence of the observed VOC levels did not negatively impact SDU performance.

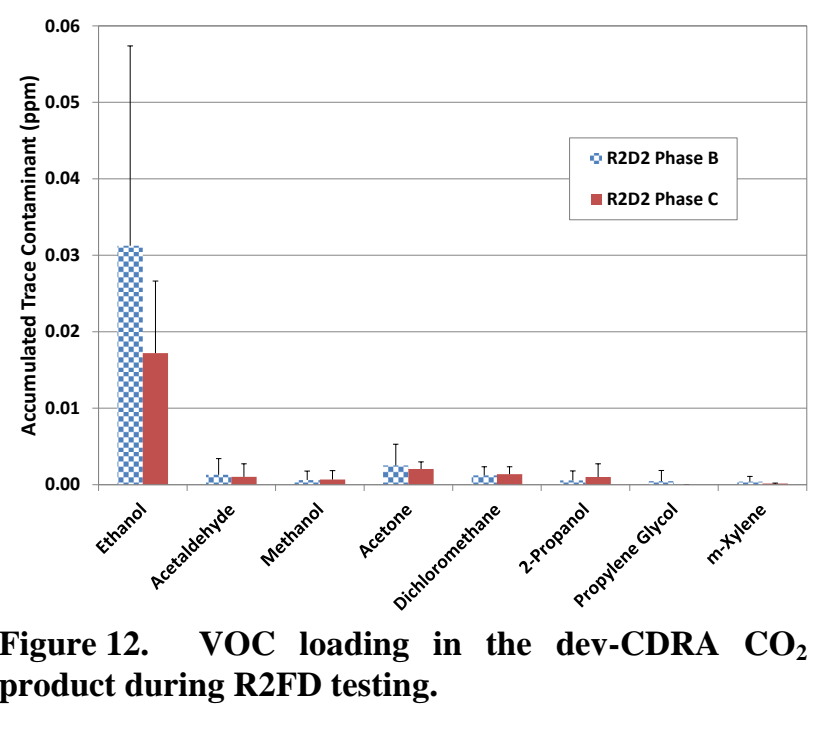

American Institute of Aeronautics and Astronautics 


\section{Cycle 1 Alternative Architecture Results Summary}

The ARREM Cycle 1 test equipment architecture incorporated changes in the trace contaminant control equipment configuration as well as incorporated contemporary adsorbent media and oxidation catalysts. As shown by Fig. 2, the trace contaminant control catalytic oxidizer was integrated directly with the dev-CDRA to provide a more efficient packaging architecture and to eliminate the need for a downstream post-sorbent bed. The catalytic oxidizer incorporated an advanced ultra-short channel metal monolith reactor design compared to the ISS catalyst pellet bed reactor design that uses a commercially obsolete platinum group metal catalyst product formerly manufactured by Engelhard Corp. The trace contaminant control activated carbon adsorbent bed was integrated in parallel with the EChamber condensing heat exchanger. Adsorbents and catalysts that have been evaluated and determined to be suitable replacements for those used in the ISS AR subsystem equipment were used during the testing. ${ }^{12-13}$ The bed was packed with Chemsorb 1425 (Molecular Products) activated carbon to replace Type 3032 (Barnebey-Sutcliffe) activated carbon that is commercially obsolete. The dev-CDRA $\mathrm{CO}_{2}$ adsorbent beds were packed with RK-38 zeolite 5A as a replacement for ASRT zeolite 5A. Downstream of the dev-CDRA, a flight like CMA piston compressor built by Southwest Research Institute was installed. These changes were designed to reduce the core AR subsystem mass and volume compared to the ISS comparison basis as well as test suitable replacements for adsorbent and catalyst media that have become commercially obsolete. Demonstrating flow rate balancing and evaluating the Cycle 1 AR subsystem architecture's performance relative to performance observed during the R2FD testing series were the primary testing objectives. The SDU was operated during the late testing phases. The devOGA was not included in the testing due to the equipment's readiness status. For this reason, as with the R2FD test, the $\mathrm{O}_{2}$ generation function was simulated.

\section{A. Test Progression and Integration Feasibility Demonstration}

The ARREM Cycle 1 testing series began by conducting a CDRA 3-point $\mathrm{CO}_{2}$ removal performance test to understand the effect of changing the $\mathrm{CO}_{2}$ adsorbent media from ASRT 5A zeolite to RK-38 5A zeolite. This testing phase was completed as planned and there were no anomalies or interruptions in facility support equipment or the dev-CDRA noted.

The next phase in the ARREM Cycle 1 testing progression focused on establishing the flow balance between the dev-CDRA and the TCCS components. The testing demonstrated the capability to establish and control the desired $6.3 \mathrm{~m}^{3} / \mathrm{h}$ flow through the TCCS components using the dev-CDRA blower to provide the motive force. The devCDRA flow was set at its normal $34.7 \mathrm{~m}^{3} / \mathrm{h}$ setpoint during the course of the flow balancing test. Establishing the desired $8.5 \mathrm{~m}^{3} / \mathrm{h}$ flow through the TCCS activated carbon bed proved to be more difficult. A booster fan was required to provide the flow. This result indicated additional options for integrating the activated carbon bed into the AR subsystem architecture to fully achieve the subsystem architectural objectives of eliminating the booster fan.

The testing progression continued with stand-alone dev-CDRA testing to evaluate the expected performance at simulated metabolic loads representative of 2, 3, 4, and 6 people. Upon completing this phase, the Southwest Research Institute's $\mathrm{CO}_{2}$ compressor was installed and functionally demonstrated. The result of the test was that the CMA met its test objective of delivering $\mathrm{CO}_{2}$ from the dev-CDRA and storing it for use by the SDU according to the ISS performance parameters.

The testing progression advanced to incorporate the TCCS, dev-CDRA, and SDU components. Similar to the R2FD test, this phase included chemical injection to determine how VOCs propagate through the core AR subsystem into the $\mathrm{CO}_{2}$ product that is to be delivered to the SDU. The TCCS component flow was through a Combined Media Catalyst Bed containing Chemsorb 1425 and Carulite 300 (Carus Corp.) catalyst due to an inadvertent testing configuration setup error. This configuration error was not discovered until post-test analysis.

The Cycle 1 core AR subsystem integrated test was conducted from 1/23/13 to 2/7/13 and consisted of pre-test days to condition the EChamber atmosphere and warm up the test articles followed by three test days at metabolic simulation rates representative of 2, 3, 4, and 6 people. Conditions in the EChamber were similar to those summarized by Table 2 with the primary difference being the range of metabolic simulation. The total test duration was twelve days allowing 72 hours of operation at each metabolic loading condition. During the test there was neither indication of contaminant carryover into the metabolic simulator $\mathrm{O}_{2}$ concentrator effluent nor contaminant buildup in the EChamber atmosphere which is an indication of a properly functioning AR subsystem. A buildup of $\mathrm{O}_{2}$ in the EChamber was noted and may be attributed to a slight imbalance in mass flow controllers for $\mathrm{O}_{2}$ removal via the Oxygen Concentrator and $\mathrm{O}_{2}$ injection to simulate the $\mathrm{O}_{2}$ generation function. 


\section{B. Carbon Dioxide Removal Performance}

As a result of an investigation into an on-orbit anomaly, the CDRA underwent several design modifications which lead to the CDRA Dash 4 (CDRA-4) configuration. One of the modifications is to replace the sorbent materials in both the desiccant beds and the adsorbent beds.

In June 2012, a 3-point performance test was conducted to provide comparative performance data for the old sorbents. Prior to the start of the ARREM Cycle 1 testing series, the ASRT 5A zeolite in the adsorbent bed was replaced with the new sorbent, RK-38 5A zeolite. For all of ARREM Cycle 1 testing through February 2013, the desiccant beds contained the old material-Grace Davison Grade 40 silica gel and 13X zeolite-while the $\mathrm{CO}_{2}$ adsorbent beds contained the new RK-38 5A zeolite. A 3-point test with the RK-38 5A zeolite installed was conducted and results were compared to past performance with the ASRT 5A zeolite installed. The 3-points were pulled from the ISS CDRA PAT Runs 12,13, and 14. These points represent various inlet concentrations of $\mathrm{CO}_{2}$. Figure 13 compares the performance of the dev-CDRA equipment when containing the ASRT and RK-38 5A zeolite materials with the ISS CDRA Protoflight unit performance.

In Fig. 13., the dotted gray line represents the required $\mathrm{CO}_{2}$ removal performance over a range of $\mathrm{CO}_{2}$ inlet concentrations. Testing the dev-CDRA packed with RK-38 5A zeolite demonstrated performance

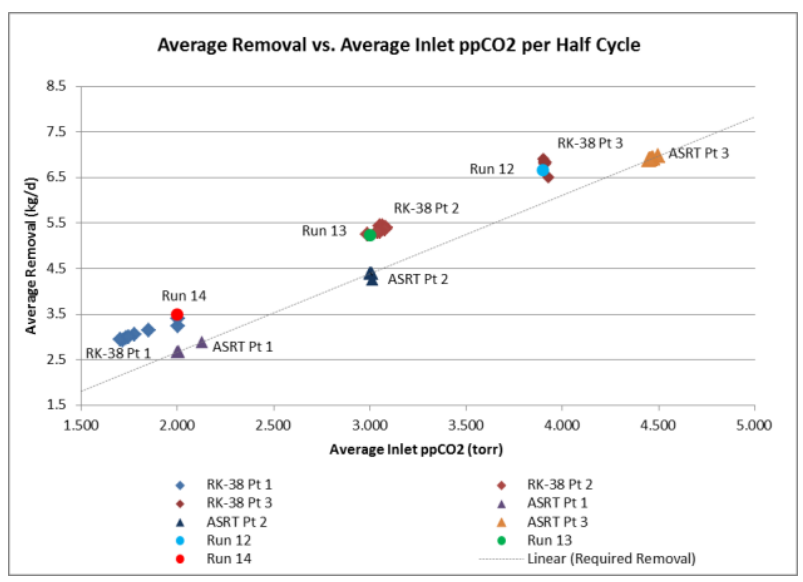

Figure 13. Adsorbent Bed Material Performance Comparison. equivalent to the performance observed during the ISS CDRA Protoflight unit performance tests. The performance of the dev-CDRA packed with ASRT 5A zeolite was approximately $16 \%$ below the performance of the ISS CDRA Protoflight test results and the dev-CDRA packed with RK-38 5A zeolite. All of the dev-CDRA equipment configurations performed within the acceptable range for meeting the ISS $\mathrm{CO}_{2}$ removal performance requirements. These tests indicate that RK-38 is an adequate alternative for the ASRT 5A zeolite.

\section{Trace Contaminant Control Performance}

The ARREM Cycle 1 total trace contaminant loading in the chamber atmosphere during test duration is shown by Fig. 14. The mean contaminant loading over the test duration was found to be 1.03 $\mathrm{ppm}$. This was a decrease of approximately $10 \%$ of the mean chamber atmosphere loading observed during the R2FD testing series. Note that unlike $\mathrm{R} 2 \mathrm{FD}$, the Cycle 1 trace contaminant injection mixture did not contain methanol or 2-propanol. Both of these compounds were experimentally measured, however. The presence of these species was attributed to residual levels persisting from the R2FD testing. The 2-propanol concentration was measured on the

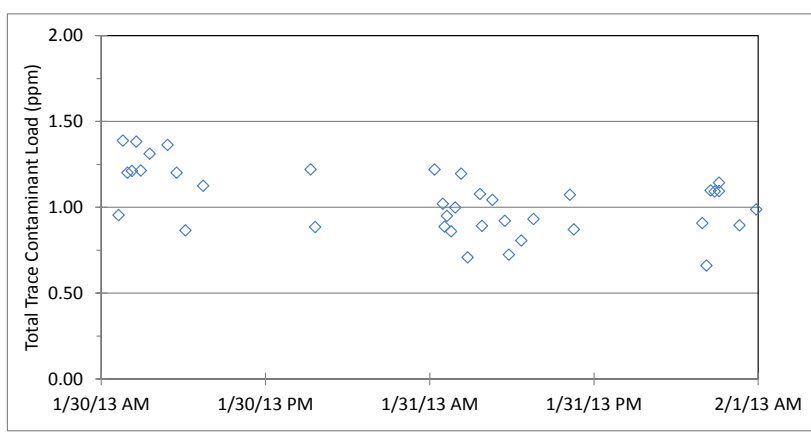

Figure 14. Total Echamber atmosphere trace contaminant loading during ARREM Cycle 1 testing.

order of $1 \mathrm{ppb}$ and this was accepted to be within the GC analytical noise level. Methanol was detected on the order of $10 \mathrm{ppb}$. If truly present as a residual contaminant, it was expected that contaminant removal routes would eliminate this chemical over time. Indeed, mean methanol levels were detected at $0.030 \mathrm{ppm}$ on $1 / 30 / 13$ and trended down to $0.021 \mathrm{ppm}$ on $1 / 31 / 13$.

Due to the physical re-configuration of the TCCS activated carbon bed and catalytic oxidizer components, TCCS performance was monitored by measuring the inlet and outlet trace contaminant loads for each individual unit. Drawing directly from the chamber atmosphere, the activated carbon bed showed a mean trace contaminant load reduction of $91.2 \%$. Table 4 displays the observed activated carbon bed performance over the test duration.

The HTCO was arranged to draw its process air flow off the dev-CDRA unit downstream of the desiccant beds. Analysis indicated that trace contaminant concentrations were reduced to concentrations ranging between $2 \mathrm{ppb}$ and $4 \mathrm{ppb}$ after the process air passed through the dev-CDRA desiccant beds. A non-methane VOC concentration reduction across the dev-CDRA desiccant beds is expected based on previous observations. ${ }^{14-15}$ Therefore, TCCS 
components integrated in this location are better suited for removing compounds such as $\mathrm{CH}_{4}$ and carbon monoxide $(\mathrm{CO})$ that are not well-removed by the desiccant bed adsorbents.

The inlet and outlet trace contaminant loads of the dev-CDRA were also monitored to determine the removal efficiency as shown in Table 5. Drawing directly from the chamber atmosphere, the dev-CDRA showed

a staggering mean trace contaminant load reduction of 99.1\%. This removal efficiency is consistent with high single-pass removals observed for 2-propanone during zeolite loading tests documented by Lockheed in 1991 and NASA in 1974 documented by Refs. 14 and 15, respectively. However, more recent testing documented by Refs. 10 and 11 indicated a trace contaminant removal dynamic associated with the cycling desiccant bed regeneration. The result observed during the ARREM Cycle 1 test is indicative of removal under a steady process condition, possibly late in the devCDRA half cycle when the adsorbent beds are at their coolest. More analysis is necessary to understand the timing of the GC samples collected from the devCDRA inlet and outlet relative to the dev-CDRA half cycle period.

In order to determine the effect of trace contaminants on the SDU, the $\mathrm{CMA} \mathrm{CO}$ accumulator tank located downstream from the dev-CDRA subsystem which buffers $\mathrm{CO}_{2}$ pressure and flow fluctuations was sampled and analyzed for VOC content. The CMA $\mathrm{CO}_{2}$ accumulator tank had a mean concentration of 0.043 ppm over this time, remarkably similar to the loading observed during the R2FD test.

Serving as a contaminant removal route, the $\mathrm{O}_{2}$ concentrator entrained trace contaminant species as shown by Fig. 15. The $\mathrm{O}_{2}$ concentrator had a mean concentration of $0.013 \mathrm{ppm}$ and trended down with testing. A linear data regression trendline serves to guide the eye.

\section{Carbon Dioxide Reduction Performance}

As shown by Fig. 16, VOC loading of accumulated $\mathrm{CO}_{2}$ was very similar during ARREM Cycle 1 testing as observed during R2FD testing. Only ethanal (acetaldehyde) showed a significant increase in ARREM Cycle 1 over R2FD. Analysis of the EChamber trace contaminant loading data does not readily indicate a root cause for the higher loading in the $\mathrm{CO}_{2}$. Overall, the results summarized by Fig. 16 indicate that the RK-38 5A zeolite behaves similarly with respect to trace contaminant removal compared to the ASRT 5A zeolite.
Table 4. Activated carbon bed performance.

\begin{tabular}{|c|c|c|c|}
\hline \multirow{2}{*}{ DATE } & \multicolumn{2}{|c|}{ CONCENTRATION } & \multirow{2}{*}{$\begin{array}{c}\text { REDUCTION } \\
(\boldsymbol{\%})\end{array}$} \\
\cline { 2 - 3 } & In (ppm) & Out $(\mathbf{p p m})$ & 92.2 \\
\hline $1 / 29 ; \mathrm{PM}$ & 0.905 & 0.071 & 89.8 \\
\hline $1 / 29-1 / 30$ & 0.731 & 0.075 & 91.3 \\
\hline $1 / 30 ; \mathrm{PM}$ & 1.033 & 0.090 & 91.5 \\
\hline $1 / 31 ; \mathrm{AM}$ & 0.765 & 0.065 & \\
\hline
\end{tabular}

Table 5. VOC removal by the dev-CDRA.

\begin{tabular}{|c|c|c|c|}
\hline \multirow{2}{*}{ DATE } & \multicolumn{2}{|c|}{ CONCENTRATION } & \multirow{2}{*}{$\begin{array}{c}\text { REDUCTION } \\
(\boldsymbol{\%})\end{array}$} \\
\cline { 2 - 3 } & In (ppm) & Out $(\mathbf{p p m})$ & 99.5 \\
\hline $1 / 29 ; \mathrm{AM}$ & 1.135 & 0.005 & 99.7 \\
\hline $1 / 29-1 / 30$ & 1.114 & 0.004 & 98.3 \\
\hline $1 / 30 ; \mathrm{PM}$ & 1.368 & 0.023 & 99.0 \\
\hline $1 / 31 ; \mathrm{AM}$ & 1.109 & 0.011 & \\
\hline
\end{tabular}

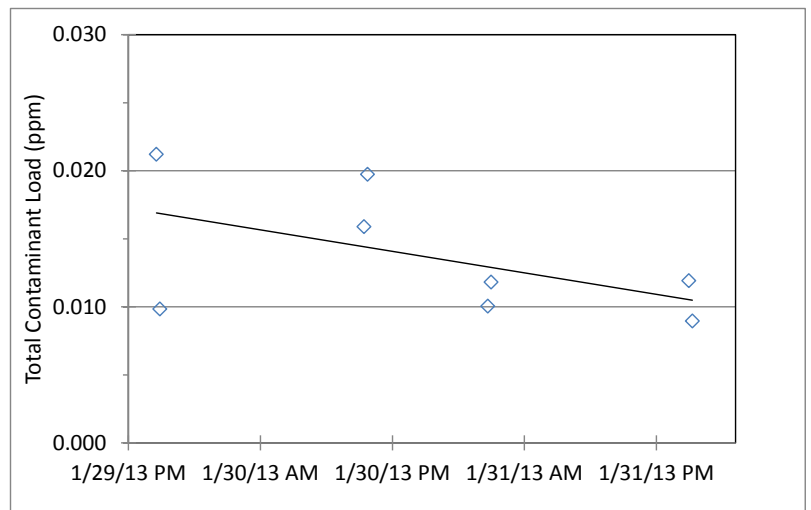

Figure 15. Oxygen concentrator trace contaminant removal during the ARREM Cycle 1

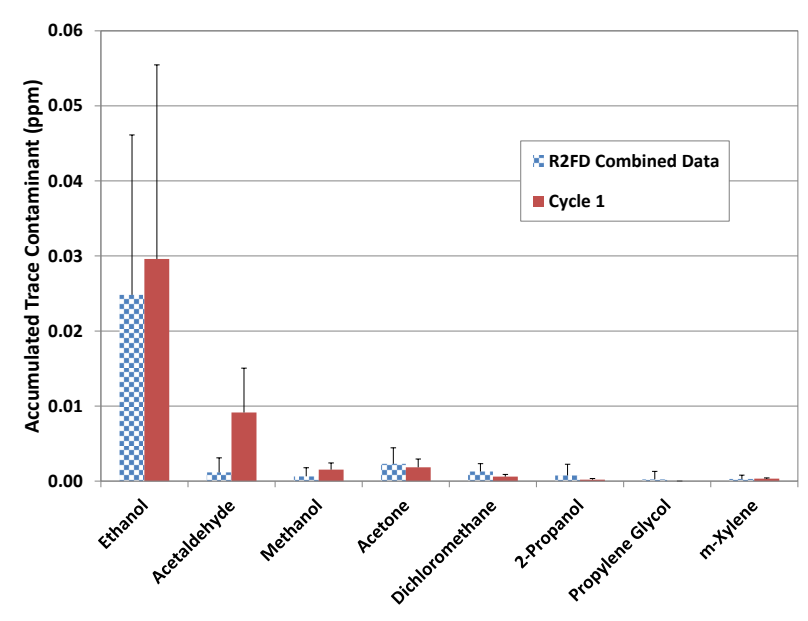

Figure 16. VOC loading of accumulated $\mathrm{CO}_{2}$. Comparison of R2FD testing and Cycle 1 testing. 


\section{Improvement for the Future}

\section{A. General Operations and Integration}

Operationally, there was very little difference between the test facility support equipment for R2FD testing and that for ARREM Cycle 1 testing. The new configuration of the TCCS components did not impact the facility's ability to achieve targeted flow rates to all areas. The one concession in that regard was the addition of a booster fan for the TCCS activated carbon bed after the initial test proved that targeted flow could not be supplied without it. Alternative integration concepts for the TCCS activated carbon bed will be investigated during future ARREM integrated testing cycles. The greatest performance gain over the R2FD configuration was the ability of Southwest Research's $\mathrm{CO}_{2}$ compressor to deliver and hold pressure in the $\mathrm{CO}_{2}$ accumulator which was a marked improvement over the commercial compressor used during R2FD testing.

\section{B. Carbon Dioxide Removal Architecture}

The desiccant beds and adsorbent beds contained in the dev-CDRA ground test unit used during both the R2FD and ARREM Cycle 1 testing series have slightly different aspect ratios and, therefore, slight size differences compared to the ISS Protoflight CDRA beds. Even so, the dev-CDRA equipment has been proven to provide valuable, comparative performance data consistent with the ISS Protoflight CDRA equipment that has proven valuable for supporting both flight operations and technology development initiatives. The dev-CDRA adsorbent beds containing ASRT 5A zeolite meet the required $\mathrm{CO}_{2}$ removal. When the dev-CDRA adsorbent beds were loaded and tested with the new RK-38 zeolite 5A, there was about a $16 \%$ increase in $\mathrm{CO}_{2}$ removal compared to the beds loaded with ASRT 5A zeolite. Thus, opportunity exists to investigate smaller adsorbent bed sizing.

Future improvements to the dev-CDRA ground test unit includes replacing the desiccant bed materials with those to be used in the ISS Protoflight CDRA-4 beds. Testing under the ARREM Cycle 1 protocol will provide further performance results on a $\mathrm{CO}_{2}$ removal process configured around those selected adsorbent media. Further improvement of the ground testing equipment includes replacing the desiccant and $\mathrm{CO}_{2}$ sorbent beds with new housings that provide the exact configuration of the ISS Protoflight CDRA-4 beds. Future ARREM testing cycles will include the higher fidelity $\mathrm{CO}_{2}$ removal equipment and the most current adsorbent media. Alternative sorbent media beyond those selected by the ISS Program for the ISS Protoflight CDRA-4 will also be considered as the ARREM testing series progresses. As well, detailed engineering analysis of the four-bed molecular sieve process as represented by the ISS CDRA indicates significant areas for reducing desiccant and $\mathrm{CO}_{2}$ sorbent bed sizing while maintaining the $\mathrm{CO}_{2}$ removal performance necessary for future crewed exploration missions. These opportunities for component mass and volume reduction will be explored with regard to their functional feasibility.

\section{Trace Contaminant Control Architecture}

The trace contaminant control architecture for future ARREM testing cycles will investigate alternative integration approaches to eliminate the booster fan that was necessary to provide flow through the activated carbon bed. As well, future TCCS component architectures will seek to incorporate commercially available, high flow capacity activated carbon bed containment components into future architectures. The dynamics associated with trace contaminant removal by the $\mathrm{CO}_{2}$ removal process needs to be studied more closely to realize the best possible integration of the core $\mathrm{CO}_{2}$ removal and trace contaminant control components.

\section{Carbon Dioxide Reduction Functionality}

Carbon dioxide reduction will continue to include higher fidelity $\mathrm{CH}_{4}$ post-processing demonstration options. Plasma methane pyrolysis, methane purification, and other post-processing stages will be evaluated independently and in integrated architectures with the SDU, dev-OGA, and dev-CDRA equipment.

\section{E. Oxygen Generation Functionality}

Technical efforts to integrate the ISS dev-OGA equipment with the ARREM core AR subsystem architecture will continue for the future. Under the ARREM Project, work pertaining to the dev-OGA ISS will address areas of operational complexity and reliability that have been identified from lessons learned through ISS flight OGA operational experience. The opportunity exists to use the dev-OGA equipment to evaluate proposed control software changes and procedural changes that may lead to more simple operations. Developing and demonstrating procedures to conduct cell stack polarization scans as a means to monitor cell stack health will be conducted. Hardware configuration changes may be addressed. These configuration changes, which focus on ways to improve equipment service life to enable deep space exploration missions may include the ability to operate in low cabin pressure 
environments, operate with a high cell stack pressure, evaluate new cell stack membrane technologies, and address reliability challenges associated with the ISS OGA hydrogen sensor.

\section{Conclusion}

An AR subsystem architecture that builds on the framework established by the ISS AR subsystem design has been developed and demonstrated. Demonstration results show that the physical architecture is feasible and that areas for improvement can still be realized to reduce overall mass, volume, and complexity.

The core subsystem architecture's performance meets or exceeds the performance attained by the ISS AR subsystem. Mass and volume savings of approximately $12 \mathrm{~kg}$ and 15 liters compared to the ISS AR subsystem were demonstrated by integrating the trace contaminant control components in a different manner. Additional savings may be possible through considering alternative integration concepts for the trace contaminant control activated carbon bed as well as incorporating results of detailed engineering analysis of the four-bed $\mathrm{CO}_{2}$ removal process architecture. Incorporating contemporary adsorbent media and adjusting process conditions may provide further mass and reliability benefits.

The environmental monitoring equipment providing the MCA function performed steadily and reliably throughout all testing phases. These instruments have the potential for providing a less complex and less massive instrumentation architecture compared to the mass spectrometry-based equipment used aboard the ISS.

Opportunity exists to demonstrate a higher degree of resource mass closure by incorporating $\mathrm{CH}_{4}$ postprocessing techniques. Further reliability for the $\mathrm{O}_{2}$ generation equipment architecture is possible by incorporating contemporary cell stack membrane materials and incorporating operational lessons learned from ISS flight experience.

\section{Acknowledgments}

The integrated AR subsystem testing and technology development efforts are funded by the National Aeronautics and Space Administration's Advanced Exploration Systems (AES) Program. The authors thank Kenny Bodkin, Paul Carothers, Dan Donovan, Bob Jones, Mike McCormick, John Thomas, and Tom Williams for their technical contributions to the integrated testing facility design, maintenance, and operations.

\section{References}

${ }^{1}$ Hodgson, E., Converse, D., Duggan, M., and Gentry, G. "Flexible Path Environmental Control and Life Support Technology-Possible First Steps to Move Beyond LEO," AIAA-2012-3443, 42 ${ }^{\text {nd }}$ International Conference on Environmental Systems, San Diego, CA, 2012.

${ }^{2}$ Metcalf, J., Peterson, L., Carrasquillo, R., and Bagdigian, R., "National Aeronautics and Space Administration (NASA) Environmental Control and Life Support (ECLS) Integrated Roadmap Development," AIAA-2012-3444, 42 ${ }^{\text {nd }}$ International Conference on Environmental Systems, San Diego, CA, 2012.

${ }^{3}$ Perry, J. L., Bagdigian, R. M., and Carrasquillo, R. L. "Trade Spaces in Crewed Spacecraft Atmosphere Revitalization System Development," AIAA 2010-6061, 40 ${ }^{\text {th }}$ International Conference on Environmental Systems, Barcelona, Spain, 2010.

${ }^{4}$ Perry, J. L., Abney, M. B., Knox, J. C., Parrish, K. J., Roman, M. C., and Jan, D. L., "Integrated Atmosphere Resource Recovery and Environmental Monitoring Technology Demonstration for Deep Space Exploration," $42^{\text {nd }}$ International Conference on Environmental Systems, San Diego, CA 2012.

${ }^{5}$ Perry, J. L., Tatara, J.D., Performance of Off-the-Shelf Technologies for Spacecraft Cabin Atmospheric Major Constituent Monitoring, NASA/TM-2004-213392.

${ }^{6}$ Perry, J. L., Tomes, K. M., and Tatara, J. D., "Thermal Catalytic Oxidation of Airborne Contaminants by a Reactor Using Ultra-Short Channel Length, Monolithic Catalyst Substrates," NASA/TM-2005-214061.

${ }^{7}$ Knox, J. C. "International Space Station Carbon Dioxide Removal Assembly Testing," SAE 2000-01-2345, 30" International Conference on Environmental Systems, 2000.

${ }^{8}$ El Sherif, D. and Knox, J. C. "International Space Station Carbon Dioxide Removal Assembly (ISS CDRA) Concepts and Advancements," SAE 2005-01-2892, 35 ${ }^{\text {th }}$ International Conference on Environmental Systems, 2005.

${ }^{9}$ Murdock, K., "Integrated Evaluation of Closed Loop Air Revitalization System Components," NASA/CR-2010-216451.

10Tatara, J., Perry, J., and Franks, G., "International Space Station System-Level Trace Contaminant Injection Test," NASA/TM-1999-209010.

${ }^{11}$ Tatara, J. D., Perry, J. L., and Franks, G. D. “Overview of the International Space Station System Level Trace Contaminant Injection Test," SAE 981665, $28^{\text {th }}$ International Conference on Environmental Systems, Danvers, MA, 1998

${ }^{12}$ Luna, B., Somi, G., Winchester, J. P., Grose, J., Mulloth, L., and Perry, J. L., "Evaluation of Commercial Off-the-Shelf Sorbents and Catalyst for Control of Ammonia and Carbon Monoxide," AIAA 2010-6062, 40 ${ }^{\text {th }}$ International Conference on Environmental Systems, Barcelona, Spain, 2010. 
${ }^{13}$ Knox, J., Gostowski, R., Watson, D., Hogan, J., King, E., and Thomas, J., "Development of Carbon Dioxide Removal Systems for Advanced Exploration Systems," AIAA-2012-3642, $42^{\text {nd }}$ International Conference on Environmental Systems, San Diego, CA, 2012.

${ }^{14}$ Ray, C. D. "Skylab Atmospheric Contamination Control," NASA TM X-64900, pp. 21-22.

${ }^{15}$ Zeppa, S. J. "Molecular Sieve Contaminant Characterization Test Report," LMSC/F280519, Lockheed Missiles and Space Co., Inc., Sunnyvale, CA, September 1991, p. 8. 